\title{
Retinal vein occlusion in retinal racemose hemangioma: a case report and literature review of ocular complications in this rare retinal vascular disorder
}

\author{
Xue-jiao Qin*, Chao Huang and Kun Lai
}

\begin{abstract}
Backgroud: Retinal racemose hemangioma $(\mathrm{RRH})$ is a rare congenital disorder that often co-occurs with other ocular complications. In this study, we present a case of RRH complicated with retinal vein obstruction in three branches and provide a review of ocular complications and associations with RRH.

Case presentation: One case of RRH is presented. Fundus examination, fluorescein angiography (FFA) and optical coherence tomography (OCT) of the patient identified Group $3 \mathrm{RRH}$ complicated with retinal vein occlusions in the superotemporal, inferotemporal, and inferonasal branches. Macular edema, which causes visual impairment, was detected. A brief literature review was also presented. The PubMed database was searched for RRH or related keywords to find reports of ocular complications or associations published on or before Dec. 31, 2013. A total of 140 papers describing 167 RRH cases were found. The mean age of diagnosis was 22.97 years. Ocular complications were mentioned in $32(19.16 \%)$ cases. Retinal vein occlusion (46.88\%) was the major ocular complication in RRH, followed by hemorrhage (34.38\%). Eight (4.79\%) cases were associated with other ocular diseases such as Sturge-Weber syndrome, Morning glory disc anomaly and macroaneurysm.
\end{abstract}

Conclusions: Although RRH is a relatively non-progressive condition, its complications may lead to vision loss and should be treated in time.

Keywords: Retinal racemose hemangioma, Retinal vein occlusion, Eye, Complication

\section{Background}

Retinal racemose hemangioma (RRH), also called retinal arteriovenous malformation [1,2] or retinal arteriovenous communication [3], is a congenital, non-hereditary, and sporadic phacomatosis that is characterized by the appearance of dilated and tortuous retinal vessels frequently extending unilaterally from the optic disc to the retinal periphery. Approximately 30\% of RRH patients have coexisting arteriovenous malformations in the brain; this condition is known as Wyburn-Mason syndrome or Bonnet-Dechaumme-Blanc syndrome [4-6]. In rare cases, vascular malformations can also be found in the skin, kidneys, bones, and muscles of RRH patients.

\footnotetext{
* Correspondence: qinxuejiao@hotmail.com

Department of Ophthalmology, Qilu Hospital of Shandong University, Box 639, 107 Wenhua Xi Road, Shandong PRC 250012, China
}

RRH was once thought to be untreatable and does not cause hemorrhage. RRH alone may not cause any symptoms, and is thought to cause vision loss via various ocular complications. This paper presents a case of RRH with retinal vein occlusion (RVO) in three branches and provides a review of ocular complications or associations reported in papers published on or before Dec. 31, 2013.

\section{Case presentation}

The current study complies with the protocols reviewed and approved by the independent ethics committee of Qilu Hospital of Shandong University and the tenets of the Declaration of Helsinki. Signed consent form was obtained from the patient.

A 58-year old male with sudden onset of blurred vision in his right eye for 10 days was examined in detail. 


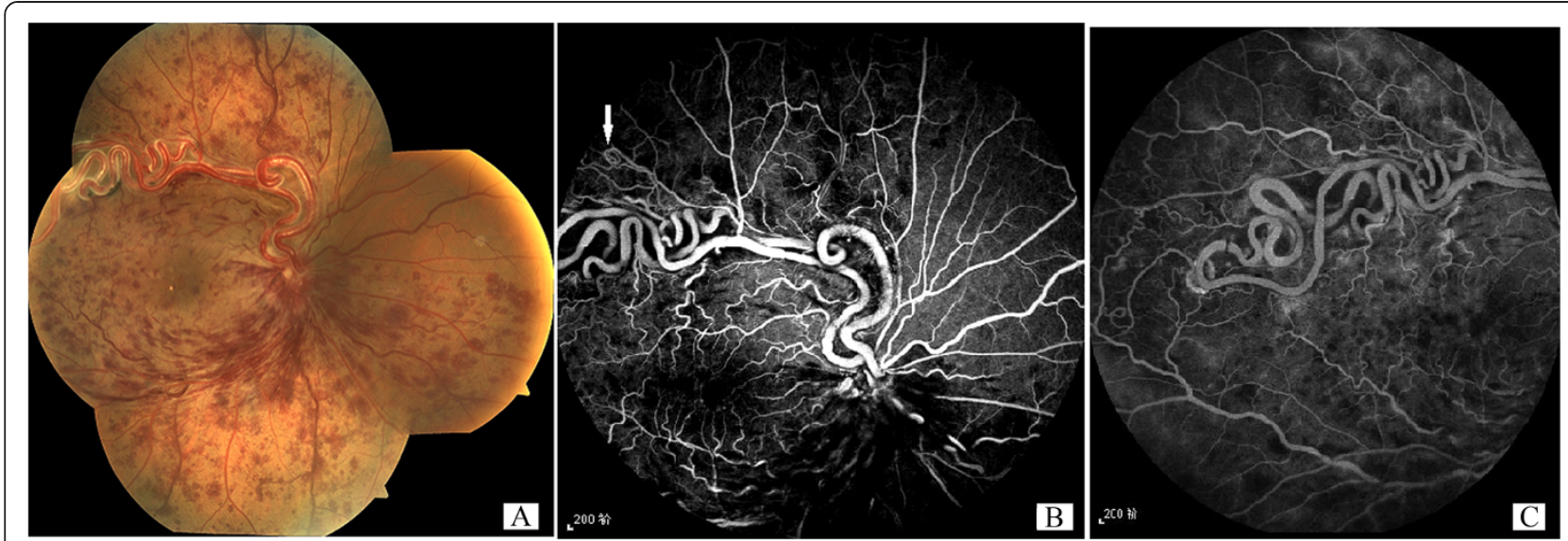

Figure 1 Fundus and FFA of the diseased eye of the patient. A: The fundus of the right eye showed a pair of enlarged and tortuous vessels extending from the optic disc. Hemorrhage was found in the temporal and inferior retina. B: FFA examination confirmed the presence of RRH and RVO in the superotemporal, inferotemporal, and inferonasal branches. $\mathbf{C}$; The communication between the pair of tortuous vessels at the temporal retina.
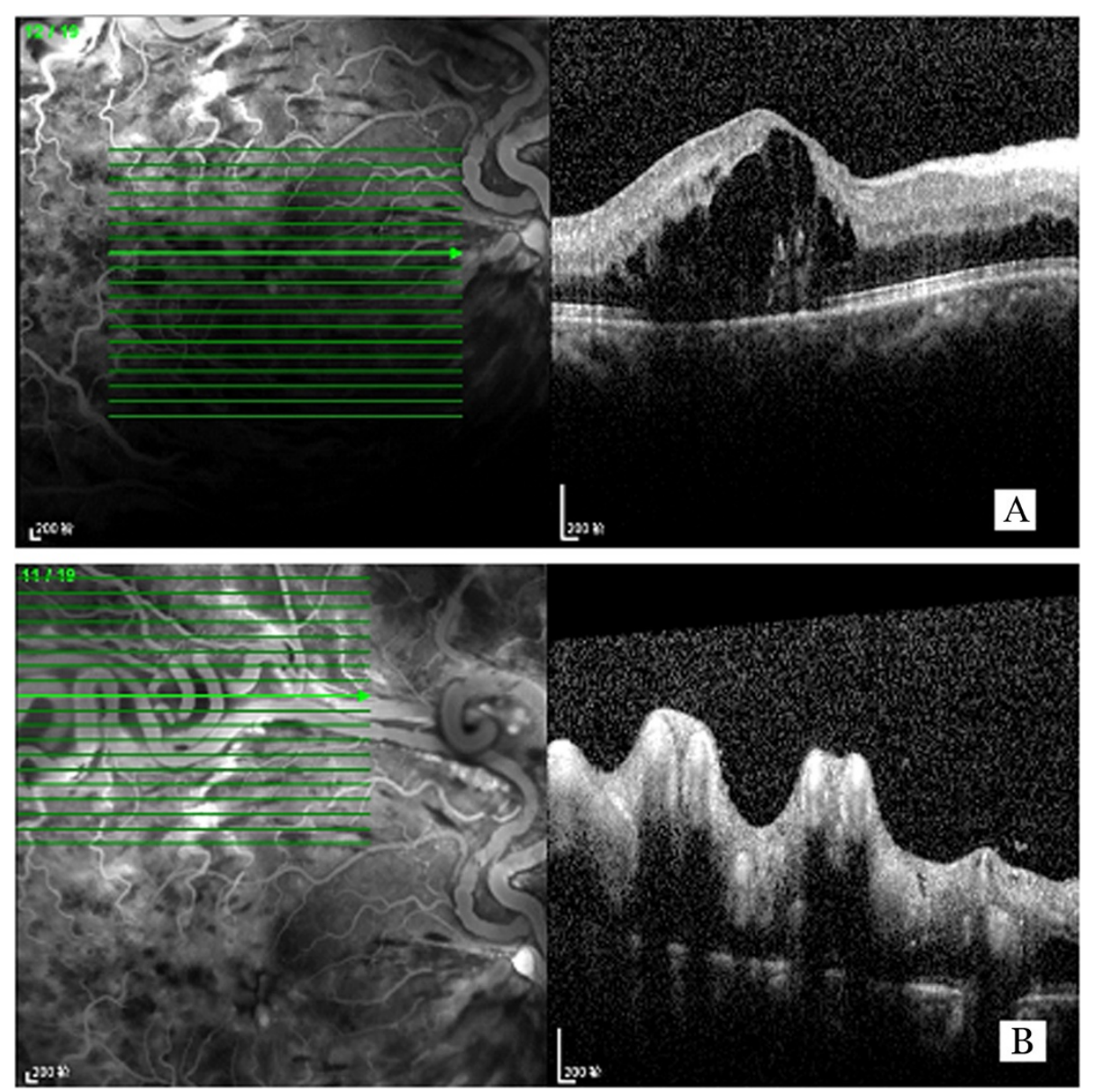

Figure $\mathbf{2}$ OCT of the diseased eye of the patient. A: cystoid macular edema was observed. B: the retinal surface was uneven in the area of distorted vessels. 
The patient had a visual acuity of 20/100 in his right eye which was not correctable (mydriatic refraction +0.75 DS) at the time of presentation. Direct light reflex of the right pupil was weak. The left eye was refractive amblyopic with a best corrected visual acuity of $20 / 40(+3.50$ DS) without any other abnormalities. The patient was previously healthy and did not take any medication. The blood pressure was $128 / 88 \mathrm{mmHg}$, the blood sugar was $5.67 \mathrm{mmol} / \mathrm{l}$, the blood lipid was slightly higher than normal (triglycerides $2.05 \mathrm{mmol} / \mathrm{l}$, low density lipoprotein cholesterol $4.30 \mathrm{mmol} / \mathrm{l})$. The fundus of the right eye showed a pair of enlarged and tortuous vessels extending from the optic disc. Flame-shaped hemorrhage was found in the temporal and inferior retina, along with dilated retinal veins, whereas macular central reflection was not identified (Figure 1A). FFA examination confirmed the presence of RRH and RVO in the superotemporal, inferotemporal, and inferonasal branches, indicating communication between the pair of tortuous vessels and hypofluorescence caused by hemorrhage and capillary nonperfusion (Figures 1B, 1C). The RRH was found to belong to Group 3 based on Archer's classification because of the absence of capillary bed between the artery and the vein [3] and because of additional vessel anastomoses in the peripheral retina (Figure 1B, arrowed). OCT examination showed cystoid macular edema (Figure 2A) due to RVO. The retinal surface was uneven in the area of distorted vessels (Figure 2B). Magnetic resonance imaging (MRI) of the brain revealed no abnormality, and abdominal ultrasonography was normal despite the presence of a liver cyst.

\section{Literature review and discussion}

Papers dated Dec. 31, 2013 or older were searched using "retinal arteriovenous communication," "retinal arteriovenous malformations", "Wyburn-Mason syndrome", "retinal arteriovenous anastomoses", "retinal racemose hemangioma", and "retinal racemose angioma" as keywords in the PubMed database by two persons. The content of each search result was thoroughly checked to ensure its relevance to the topic of the study, especially for papers with ambiguous title. Non-English papers with expressions related to RRH in the English title, abstract, or keywords were included. Papers in Chinese were checked by reading the full text. Papers concerning complications in the eye of patients with RRH were recorded and analyzed.

PubMed search yielded 499 papers related to RRH. Except for reports on "Wyburn-Mason syndrome without retinal involvement", 140 results (167 cases) were related to RRH, including so called "convoluted vessels", "twin vessel", "racemose aneurysm of retina", and "retinal arteriovenous aneurysm". Secondary arteriovenous communications were also excluded. Of the 167 cases mentioned in these papers, 152 reported the sex of the subjects
Table 1 Ocular complications and associations of retinal racemose hemangioma

\begin{tabular}{|c|c|c|}
\hline Total RRH $=167$ cases & $\begin{array}{l}\text { Cases (percentage } \\
\text { of total) }\end{array}$ & References \\
\hline Complications & $32(19.16 \%)$ & \\
\hline Retinal vein occlusion & $15(46.88 \%)$ & \\
\hline CRVO & 8 & {$[1,2,9-13]$} \\
\hline CRVO & 4 & {$[7,12,14,15]$} \\
\hline Hemi-central & 1 & {$[16]$} \\
\hline Three Branches & 2 & {$[17]$, this report } \\
\hline Hemorrhage & $11(34.38 \%)$ & \\
\hline Vitreous & 5 & {$[12,18,19]$} \\
\hline Intra/sub-retinal & 2 & {$[12,20]$} \\
\hline Macular & 4 & {$[7,18]$} \\
\hline Rubeotic Glaucoma & $2(6.25 \%)$ & {$[12,21-23]$} \\
\hline Macular edema & $3(9.38 \%)$ & {$[8,24,25]$} \\
\hline Retinal detachment & $1(3.13 \%)$ & \\
\hline $\begin{array}{l}\text { Rhegmatogenous } \\
\text { retinal detachment }\end{array}$ & 1 & {$[26]^{*}$} \\
\hline Associations & $8(4.79 \%)$ & \\
\hline Morning glory disc anomaly & $2(25 \%)$ & {$[27,28]$} \\
\hline Macular hole & $1(12.5 \%)$ & [29] \\
\hline Sturge-Weber syndrome & $2(25 \%)$ & {$[30,31]$} \\
\hline Vogt-Koyanagi-Harada syndrome & $1(12.5 \%)$ & {$[32]$} \\
\hline $\begin{array}{l}\text { Duane type I } \\
\text { retraction syndrome }\end{array}$ & $1(12.5 \%)$ & [33] \\
\hline Macroaneurysm & $1(12.5 \%)$ & {$[34]$} \\
\hline
\end{tabular}

*It was hypothesized that vitreous hemorrhage over a long period may have preceded this.

(84, 55.26\% females and $68,44.74 \%$ males), 128 reported the age of diagnosis (range, 4 to 71 years; mean, 22.97 years), and 3 (1.79\%) reported having bilateral occurrence of the disease $[7,8]$. Ocular complications or associations are summarized in Table 1 . For patients with neovascular glaucoma secondary to RVO, only RVO was recorded. Ocular complications were reported in 32 $(19.16 \%)$ cases, whereas ocular associations were reported in 8 (4.79\%) cases.

Retinal vascular tumors are classified into four clinical categories, including retinal capillary hemangioma, retinal cavernous hemangioma, $\mathrm{RRH}$, and retinal vasoproliferative tumor [35-37]. As a phacomatosis disorder, RRH can manifest at an early age. The average age determined by the current study is 22.97 years old, which is similar to the mean age of 23 years from 27 patients with WyburnMason syndrome reported by Dayani and Sadun [38]. The average age determined by the current study in patients with RRH is significantly younger than the average age of 42 years from $13 \mathrm{RRH}$ patients in the study by Mansour et al. (7), who also reported the disease as "arteriovenous 
anastomoses of the retina". Retinal vascular abnormality usually exhibits no symptoms, and is not easily determined compared with malformations in other body parts. Patel (40) reported a case of Wyburn-Mason syndrome with vascular abnormalities in the face, orbit, and brain (but not in the retina) of a newborn. RRH was once thought to be non-progressive, and patients can often continue to have good vision [39,40]. The longest follow-up period was 27 years without any progression in the retinal or cephalic condition [40]. A case of self-regression was also reported [41]. However, previous reports indicated that vessel dilation and elongation would occur over time in previously normal vessels [42] and that visual impairment would occur because of late ocular complications, particularly ischemic complications $[14,17,21]$. The current study found that RVO is the most common complication of RRH. RVO accounted for $45.46 \%$ of the total number of complication cases, while hemorrhage only accounted for $33.33 \%$. Venous occlusion in RRH was attributed mainly to abnormal turbulent blood flow in the veins. In patients with $\mathrm{RRH}$, the veins that connect directly to the arteries are subjected to arterial blood pressure. High blood pressure causes irregular venous wall thickening, endothelial damage and proliferation, and thrombosis [43]. In some cases, severe thrombosis and further fibrosis can cause the malformed vessels to close spontaneously [44-46]. In the present study, the superotemporal, inferotemporal, and inferonasal venous branches were found to converge into a single trunk while the superonasal venous branch drained to another trunk in the disc. This phenomenon is called incomplete central retinal vein occlusion. The elevated level of blood lipid in this patient may also have induced the development of RVO. RVO is also considered a complication of cerebral arteriovenous malformation [47]. RVO and other related macular edema or secondary neovascular glaucoma are all vision-threatening conditions. Although racemose hemangioma is not easily treated, its complications should be handled accordingly to retard vision deterioration. Procedures for slowing vision deterioration include laser therapy for RVO, retrobulbar or intraocular injection of triamcinolone for macular edema, vitrectomy for vitreous hemorrhage, and drainage valve implantation for glaucoma. New anti-vascular endothelial growth factor agents have been tested for treatment of malformed vessels or macular edema complicated with RVO [24,48-50]. However, the association of RRH with other congenital vascular malformations, such as SturgeWeber syndrome and macroaneurysm, continues to make it a challenging condition for doctors.

\section{Conclusion}

As a congenital disorder, RRH may complicate or associate with various ocular conditions; clinicians should pay attention to these conditions and take action to preserve vision.

\section{Consent}

Written informed consent was obtained from the patient for publication of this case report and any accompanying images. A copy of the written consent is available for review by the Editor of this journal.

\section{Abbreviations}

(RRH): Retinal racemose hemangioma; (RVO): Retinal vein occlusion; (FFA): Fluorescein angiography; (OCT): Optical coherence tomography; (MRI): Magnetic resonance imaging.

\section{Competing interests}

The authors declare that they have no competing interest.

\section{Authors' contributions}

XJQ conceived the study; XJQ and CH conducted the clinical examinations; XJQ and $\mathrm{KL}$ conducted the PubMed search, data analysis, and data interpretation; $\mathrm{XJQ}, \mathrm{CH}$, and $\mathrm{KL}$ wrote and revised the manuscript. All authors read and approved the final manuscript.

\section{Acknowledgements}

The Project was sponsored partly by the Natural Science Foundation of Shandong Province (ZR2012HM024) and Independent Innovation Foundation to Universities and Colleges by Jinan Science and Technology Bureau (201202036). The funders had no role in study design, data collection and analysis, decision to publish, or preparation of the manuscript.

Received: 4 May 2014 Accepted: 8 August 2014

Published: 21 August 2014

\section{References}

1. Hardy TG, O'Day J: Retinal arteriovenous malformation with fluctuating vision and ischemic central retinal vein occlusion and its sequelae: 25-year follow-up of a case. J Neuroophthalmol 1998, 18(4):233-236.

2. Schatz H, Chang LF, Ober RR, McDonald HR, Johnson RN: Central retinal vein occlusion associated with retinal arteriovenous malformation. Ophthalmol 1993, 100(1):24-30

3. Archer DB, Deutman A, Ernest JT, Krill AE: Arteriovenous communications of the retina. Am J Ophthalmol 1973, 75(2):224-241.

4. Wyburn-Mason R: Arteriovenous aneurysm of midbrain and retina, facial nevi and mental changes. Brain Dev 1943, 66:40.

5. Muthukumar N, Sundaralingam MP: Retinocephalic vascular malformation: case report. Br J Neurosurg 1998, 12(5):458-460.

6. Theron J, Newton TH, Hoyt WF: Unilateral retinocephalic vascular malformations. Neuroradiol 1974, 7(4):185-196.

7. Mansour AM, Walsh JB, Henkind P: Arteriovenous anastomoses of the retina. Ophthalmol 1987, 94(1):35-40.

8. Soliman W, Haamann P, Larsen M: Exudation, response to photocoagulation and spontaneous remission in a case of bilateral racemose haemangioma. Acta Ophthalmol Scand 2006, 84(3):429-431.

9. Du B, Gu X, Zeng J: [Retinal vein occlusion with retinal arteriovenous communications]. Yan Ke Xue Bao 1996, 12(4):202-203.

10. Khairallah M, Allagui M, Chachia N: [Congenital retinal arteriovenous fistula and central retinal vein occlusion]. J Fr Ophtalmol 1993, 16(2):117-121.

11. Zylbermann R, Rozenman Y, Silverstone BZ, Ronen S, Berson D: Central retinal vein occlusion in a case of arteriovenous communication of the retina. Ann Ophthalmol 1984, 16(9):825-828.

12. Mansour AM, Wells CG, Jampol LM, Kalina RE: Ocular complications of arteriovenous communications of the retina. Arch Ophthalmol 1989, 107(2):232-236.

13. Lee AW, Chen CS, Gailloud P, Nyquist P: Wyburn-Mason syndrome associated with thyroid arteriovenous malformation: a first case report. AJNR Am J Neuroradiol 2007, 28(6):1153-1154.

14. Shah GK, Shields JA, Lanning RC: Branch retinal vein obstruction secondary to retinal arteriovenous communication. Am J Ophthalmol 1998, 126(3):446-448.

15. Federici T, Batlle I: Periocular triamcinolone acetonide as treatment for macular edema secondary to branch vein occlusion associated with retinal arteriovenous malformation. Retina 2006, 26(9):1079-1080. 
16. Yang C, Liu YL, Dou HL, Lu XR, Qian F, Zhao L: Unilateral hemi-central retinal vein obstruction associated with retinal racemose angioma. Jpn J Ophthalmol 2009, 53(4):435-436.

17. Salati C, Ferrari E, Basile R, Virgili G, Menchini U: Retinal vein occlusion: late complication of a congenital arteriovenous anomaly. Ophthalmologica 2002, 216(2):151-152.

18. Bernth Petersen P: Racemose haemangioma of the retina. Report of three cases with long term follow-up. Acta Ophthalmol (Copenh) 1979, 57(4):669-678

19. Vedantham $V$, Agrawal D, Ramasamy K: Premacular haemorrhage associated with arteriovenous communications of the retina induced by a valsalva-like mechanism: an observational case report. Indian 」 Ophthalmol 2005, 53(2):128-130.

20. Papageorgiou KI, Ghazi-Nouri SM, Andreou PS: Vitreous and subretinal haemorrhage: an unusual complication of retinal racemose haemangioma. Clin Experiment Ophthalmol 2006, 34(2):176-177.

21. Effron L, Zakov ZN, Tomsak RL: Neovascular glaucoma as a complication of the Wyburn-Mason syndrome. J Clin Neuroophthalmol 1985, 5(2):95-98.

22. Bloom PA, Laidlaw A, Easty DL: Spontaneous development of retinal ischaemia and rubeosis in eyes with retinal racemose angioma. $\mathrm{Br} J$ Ophthalmol 1993, 77(2):124-125.

23. De Jong PT: Neovascular glaucoma and the occurrence of twin vessels in congenital arteriovenous communications of the retina. Doc Ophthalmol 1988, 68(3-4):205-212.

24. Winter E, Elsas T, Austeng D: Anti-VEGF treating macular oedema caused by retinal arteriovenous malformation - a case report. Acta Ophthalmol 2012, 92(2):192-193.

25. Onder HI, Alisan S, Tunc M: Serous Retinal Detachment and Cystoid Macular Edema in a Patient with Wyburn-Mason Syndrome. Semin Ophthalmol 2013, Epub ahead of print.

26. Medina FM, Maia OO Jr, Takahashi WY: Rhegmatogenous retinal detachment in Wyburn-Mason syndrome: case report. Ara Bras Oftalmol 2010, 73(1):88-91.

27. Cordonnier M, Van Nechel C, Baleriaux D, Brotchi J: [Association of the Wyburn-Mason and morning glory syndromes]. Bull Soc Belge Ophtalmol 1987, 225(Pt 2):63-69.

28. Brodsky MC, Wilson RS: Retinal arteriovenous communications in the morning glory disc anomaly. Arch Ophthalmol 1995, 113(4):410-411.

29. Munoz FJ, Rebolleda G, Cores FJ, Bertrand J: Congenital retinal arteriovenous communication associated with a full-thickness macular hole. Acta Ophthalmol (Copenh) 1991, 69(1):117-120.

30. Shin GS, Demer JL: Retinal arteriovenous communications associated with features of the Sturge-Weber syndrome. Am J Ophthalmol 1994, 117(1):115-117.

31. Ward JB, Katz NN: Combined phakomatoses: a case report of Sturge-Weber and Wyburn-Mason syndrome occurring in the same individual. Ann Ophthalmol 1983, 15(12):1112-1116.

32. Manger CC 3rd, Ober RR: Retinal arteriovenous anastomoses in the Vogt-Koyanagi-Harada syndrome. Am J Ophthalmol 1980, 89(2):186-191.

33. Vucic D, Kalezic T, Kostic A, Stojkovic M, Risimic D, Stankovic B: Duane type I retraction syndrome associated with Wyburn-Mason syndrome. Ophthalmic Genet 2013, 34(1-2):61-64

34. Tilanus MD, Hoyng C, Deutman AF, Cruysberg JR, Aandekerk AL: Congenital arteriovenous communications and the development of two types of leaking retinal macroaneurysms. Am J Ophthalmol 1991, 112(1):31-33.

35. Singh AD, Rundle PA, Rennie I: Retinal vascular tumors. Ophthalmol Clin North Am 2005, 18(1):167-176. X.

36. Turell ME, Singh AD: Vascular tumors of the retina and choroid: diagnosis and treatment. Middle East Afr J Ophthalmol 2010, 17(3):191-200.

37. De Laey JJ, Hanssens M, Brabant P, Decq L, De Gersem R, Hoste A, Huyghe P, Lenaerts $V$, Leys $M$, Pollet $L$ : Vascular tumors and malformations of the ocular fundus. Bull Soc Belge Ophtalmol 1990, 225(Pt 1):1-241.

38. Dayani PN, Sadun AA: A case report of Wyburn-Mason syndrome and review of the literature. Neuroradiol 2007, 49(5):445-456.

39. Leitao Guerra RL, Leitao Guerra CL, Guerra M, Guerra Neto AS, Leitao Guerra AA [Retinal racemose hemangioma (Wyburn-Mason syndrome)-a patient ten years follow-up: case report]. Arq Bras Oftalmol 2009, 72(4):545-548.

40. Schmidt D, Agostini H, Schumacher M: Twenty-seven years follow-up of a patient with congenital retinocephalofacial vascular malformation syndrome and additional congenital malformations (Bonnet-Dechaume-
Blanc syndrome or Wyburn-Mason syndrome). Eur J Med Res 2010, 15(2):89-91.

41. Dekking HM: Arteriovenous aneurysm of the retina with spontaneous regression. Ophthalmologica 1955, 130(2):113-115.

42. Pauleikhoff $D$, Wessing $A$ : Arteriovenous communications of the retina during a 17-year follow-up. Retina 1991, 11(4):433-436.

43. Pile-Spellman JM, Baker KF, Liszczak TM, Sandrew BB, Oot RF, Debrun G, Zervas NT, Taveras JM: High-flow angiopathy: cerebral blood vessel changes in experimental chronic arteriovenous fistula. AJNR Am J Neuroradiol 1986, 7(5):811-815.

44. Cameron $\mathrm{ME}$, Greer $\mathrm{CH}$ : Congenital arterio-venous aneurysm of the retina A post mortem report Br J Ophthalmol 1968, 52(10):768-772.

45. Knecht PB, Bosch MM, Helbig H: Fibrotic racemose haemangioma of the retina. Klin Monbl Augenheilkd 2008, 225(5):495-496.

46. Gregersen E: Arteriovenous aneurysm of the retina. A case of spontaneous thrombosis and healing. Acta Ophthalmol (Copenh) 1961, 39:937-939.

47. Hashimoto M, Yokota A, Matsuoka S, Tsukamoto Y, Higashi J: Central retinal vein occlusion after treatment of cavernous dural arteriovenous malformation. AJNR Am J Neuroradiol 1989, 10(5 Suppl):S30-S31.

48. Chuang LH, Wang NK, Chen YP, Wu WC, Lai CC: Mature vessel occlusion after anti-VEGF treatment in a retinal arteriovenous malformation. BMC Ophthalmol 2013, 13(1):60

49. Knutsson KA, De Benedetto U, Querques G, Del Turco C, Bandello F, Lattanzio R: Primitive retinal vascular abnormalities: tumors and telangiectasias. Ophthalmologica 2012, 228(2):67-77.

50. Mitry D, Bunce C, Charteris D: Anti-vascular endothelial growth factor for macular oedema secondary to branch retinal vein occlusion. Cochrane Database Syst Rev 2013, 1, CD009510.

\section{doi:10.1186/1471-2415-14-101}

Cite this article as: Qin et al.: Retinal vein occlusion in retinal racemose hemangioma: a case report and literature review of ocular complications in this rare retinal vascular disorder. BMC Ophthalmology 2014 14:101.

\section{Submit your next manuscript to BioMed Central and take full advantage of:}

- Convenient online submission

- Thorough peer review

- No space constraints or color figure charges

- Immediate publication on acceptance

- Inclusion in PubMed, CAS, Scopus and Google Scholar

- Research which is freely available for redistribution 